\title{
PENGARUH INTERVENSI ENCHANCE RECOVERY AFTER SURGERY PADA POSTOPERATIVE TERHADAP LENGTH OF STAY: A SYSTEMATIC REVIEW
}

\author{
Jikrun Jaata \\ Dosen Institut Kesehatan dan Teknologi Graha Medika \\ Email: psmikjikrun@gmail.com
}

\begin{abstract}
Abstrak
Latar Belakang: Masalah kesehatan yang timbul pasca operasi harus segera diatasi untuk mempercepat proses pemulihan dan meminimalkan komplikasi pembedahan sehingga dapat mengurangi lama rawat inap di rumah sakit. Intervensi Enhanced Recovery After Surgery (ERAS) telah diperkenalkan pada perioperatif untuk mengurangi hari rawat inap. Tujuan: Untuk mengetahui pengaruh intervensi ERAS pada postoperative terhadap Length Of Stay (LOS). Sumber Data: ulasan sistematik ini dilakukan dibeberapa data base internasional yang diterbitkan dari tahun 2010 sampai 2019 di Pubmed, Proquest, Google Scholar, dan Science Direct yang dimulai penelusuran pada tanggal 01 sampai 31 Juli 2019. Metode: tinjauan sistematis menggunakan daftar periksa PRISMA, kemudian pertanyaan penelitian disusun menggunakan PICO pada pencarian artikel sehingga diperoleh 11 artikel memenuhi kriteria inklusi lalu dianalisis menggunakan CASP. Hasil: Terdapat 7 dari 11 artikel yang telah diulas intervensi protokol ERAS pada fase postoperative mengurangi lama hari rawat setelah diberikan intervensi dan ada perbedaan antara kelompok perlakuan dan kelompok konvensional. Sementara 4 artikel diberikan intervensi mobilisasi dini yang merupakan bagian dari ERAS pada fase postoperative terdapat 2 artikel yang setelah diberikan intervensi juga mengurangi lama hari rawat dan sisanya 2 artikel tidak ada perbedaan lama hari rawat. Namun demikain, artikel yang telah diulas tidak diketahui item mana pada protokol ERAS fase postoperative yang menyebabkan berkurangnya lama hari rawat dan masih memerlukan penelitian lebih untuk melihat pengaruh tiap item pada protokol ERAS fase postoperative. Kesimpulan: intervensi ERAS pada fase postoperative mengurangi lama hari rawat.
\end{abstract}

Kata kunci: laparatomi, operasi abdominal, operasi kolorectal, ERAS, mobilisasi dini, length of stay.

\begin{abstract}
Background: Health problems arising in the post-operation must be addressed immediately to speed up the recovery process and minimize surgical complications thereby reducing the length of stay in hospital. Enhanced Recovery After Surgery (ERAS) interventions have been introduced to perioperative to reduce hospitalization days. Objective: this study aims to determine the effect of postoperative ERAS interventions on Length of Stay (LOS). Data Source: This systematic review was carried out in several international data bases published from 2010 to 2019 on Pubmed, Proquest, Google Scholar, and Science Direct which began searching on 01 to 31 July 2019. Method: a systematic review using the PRISMA checklist, then the research questions were arranged using PICO in the search for articles so that 11 articles met the inclusion criteria and then analyzed using CASP. Results: There were 7 out of 11 articles that had reviewed ERAS protocol interventions in the postoperative phase reducing the length of stay after the intervention was given and there were differences between the treatment group and the conventional group. While 4 articles were given early mobilization interventions which were part of ERAS in the postoperative phase there were 2 articles which after given the intervention also reduced the length of stay and the remaining 2 articles there was no difference in length of stay. However, the articles that have been reviewed are not known which items in the postoperative phase ERAS protocol cause a reduction in length of stay so that they become recommendations for research by looking at the effect of each item on the postoperative phase ERAS protocol. Conclusion: ERAS intervention in the postoperative phase reduces the length of stay.
\end{abstract}

Keywords: laparotomy, abdominal surgery, colorectal surgery, ERAS, early mobilization, length of stay.

PENDAHULUAN

Volume 9, Nomor 1, Februari 2021 
Laparatomi merupakan suatu tindakan pembedahan untuk mendapatkan akses ke rongga peritoneum yang dibuat luka besar digaris tengah sepanjang linea alba (Barrow et al., 2013). Tindakan laparatomi di Amerika Serikat antara tahun 2009-2013 ada sekitar 10 juta pasien yang menjalani operasi (Carney, Weissler, Fox, Tecce, \& John, 2017) sedangkan di Inggris tahun 2013 prosedur pembedahan sekitar 30.000 hingga 50.000 dilakukan setiap tahun (Barrow et al., 2013) Sementara di Indonesia tindakan pembedahan mencapai 1,2 juta jiwa per tahun dan diperkirakan $32 \%$ diantaranya merupakan tindakan bedah laparotomi (Depkes, 2013). Dari tindakan pembedahan angka morbiditas dan mortalitas diperkiran diperkirakan berjumlah 3-16\% dengan kematian 0,4$0,8 \%$ dinegara maju, sementara di negara berkembang diperkirakan jauh lebih tinggi berkisar 5-10\% (Darmawan \& Rihiantoro, 2017). Berdasarkan hasil tabulasi Nasional Depkes (2011) tindakan pembedahan meningkat 20\% dari 1.320 kasus menjadi 1.567 kasus (Sjamsuhidarat, Karnadihardja, Prasetyono, \& Rudiman, 2010).

Meningkatnya tindakan pembedahan, seiring dengan masalah kesehatan yang akan ditimbulkan postoperative yaitu berbagai komplikasi diantaranya ileus pasca operasi, kejadian tromboemboli, kelemahan otot, gangguan pulmonary, infeksi intraabdominal, perdarahan, kebocoran anastomose, infeksi luka, luka dehisens, sistem nervus sentral, infeksi urogenital (Tengberg et al., 2017). komplikasikomplikasi yang ditimbulkan dapat memperpanjang lama hari rawat atau length of stay (LoS) dan akan menentukan progresivitas masalah kesehatan.
Masalah kesehatan yang ditimbulkan pada postoperative harus segera ditangani untuk mengurangi efek dari komplikasi sehingga mengurangi LoS yakni dengan intervensi Enhanced Recovery After Surgery (ERAS) termaksud diantaranya mobilisasi dini yang merupakan bagian dari ERAS pada fase postoperative yang berkontribusi terhadap proses pemulihan pasien sehingga mendapat nilai rekomendasi yang kuat dari Enhanced Recovery after Surgery Society sebagai pedoman perawatan perioperative (Ahmed \& Elzohry, 2018).

Berdasarkan pedoman praktis klinis dari American Society of Colon and Rectal Surgeons (ASCRS) dan Society of American Gastrointestinal and Endoscopic Surgeons (SAGES) manajemen intervensi ERAS khususnya pada fase postoperative termasuk juga mobilisasi dini dapat digunakan dalam meminimalkan beberapa dampak negatif dari operasi pada fungsi organ (Carmicahel et al., 2017). Untuk itu sering digunakan dalam praktik klinis guna meningkatkan kinerja pada perioperatif untuk mempercepat proses pemulihan sehingga mengurangi LoS (Olle, Tonia, \& Demartines, 2017), sehingga yang menjadi fokus ulasan dalam literatur ini yaitu protokol ERAS pada fase postoperative terhadap LoS.

\section{METODE PENELITIAN}

Dalam ulasan sistemitik ini penulis menentukan kriteria studi yang akan diulas yaitu (1) pasien mendapatkan semua intervensi ERAS pada fase postoperative atau pasien yang hanya mendapatkan intervensi mobilisasi dini yang merupakan bagian ERAS pada fase posoperative, (2) studi penelitian kuantitatif, (3) studi yang dilakukan dalam 10 tahun terakhir, (5) publikasi studi penggunaan bahasa Inggris dan studi yang dipublikasi international (6) 
membahas length of stay. Penulis juga menentukan kriteria ekslusi yaitu (1) populasi pasien anak dengan umur kurang dari 17 tahun (2) studi publikasi dengan penggunaan bukan bahasa Inggris (3) studi yang bukan studi kuantitatif (4) intervensi protokol ERAS pada preopertif, dan intraoperative) (5) pemberian intervensi tunggal pada ERAS postoperative terkecuali mobilisasi dini

Tinjauan literatur melalui penelusuran hasil-hasil publikasi ilmiah dengan database Pubmed, Sciencedirect, Proquest, dan Google Scholar kemudian menggunakan metode PICOT (patient, intervention, comparison, outcome, and time) yakni untuk meningkatkan ketepatan dan kelengkapan pelaporan studi intervensi. Adapun Kata kunci PICOT yang digunakan saat pencarian berdasarkan database di MeSH Term yaitu : $\mathrm{P}$ (laparotomy OR abdominal surgery OR colorectal surgery), I (ERAS OR early mobilization) dan $\mathrm{O}$ (length of stay) (Cohen et al., 2016).

Pedoman dalam menganalisis kualitas artikel menggunakan Critical Appraisal Skill Programe Tools/ CASP meliputi Randomized Controlled Trial (RCT) checklist sebanyak 11 pertanyaan (CASP, 2018a), case control study checklist 11 pertanyaan (CASP, 2018c), cohort study checklist 12 pertanyaan (CASP, 2018b). Tujuan dari penilian ini untuk menilai kualitas metodologis dari suatu penelitain dan untuk menentukan sejauh mana suatu penelitian telah membahas kemungkinan bias dalam desain, perilaku dan analisisnya. Hasil dari penelaian ini kemudian dapat digunakan untuk menginformasikan sintesis dan intrepretasi hasil penelitian.

Pada penelitian ini alat ekstraksi data dirancang untuk memandu

Tabel 1

Kisi Sintesa informasi dari cacatan sesuai dengan tujuan penelitian. Data yang diekstraksi pada setiap studi yang di inklusi meliputi penulis penulis, tahun, Negara, populasi dan setting, desain studi, tujuan penelitian, metode dan intervensi, hasil serta outcome yang di hasilkan dari tiap studi.

Tinjauan sistematis adalah metode yang digunakan dalam penulisan ini dengan melakukan sintesis narasi dari temuan utama yaitu berkurangnya lama hari rawat setelah dilakukan intervensi ERAS pada fase postoperative yakni mobilisasi dini. Penulisan laporan ulasan sistematik ini berdasarkan pedoman PRISMA untuk protokol peninjauan serta pemilihan studi. Pedoman PRISMA merupakan alat instrument yang berdasarkan bukti item untuk pelaporan dalam tinjauan sistematis dan meta analisis (Moher et al., 2009).

Penulis menilai semua artikel yang diidentifikasi secara independen untuk dimasukkan dalam tinjauan sistematik. Sebanyak 3464 artikel yang berpotensi relevan telah diidentifikasi. 3368 artikel dieksklusi, karena hanya mengambil 100 artikel paling atas di tiap data based (ScienceDirect, Proquest, Google Scolar), double publikasi dan study yang tidak sesuai dengan tujuan studi ini. Selanjutnya, 83 artikel dieksklusi karena tidak full text dan tidak relevan dengan tujuan penelitian). Sehingga ditemukan artikel yang memenuhi kriteria inklusi sebanyak 11 artikel. Gambar 1 menggambarkan proses inklusi studi yang terdiri dari 4 artikel studi Randomised Controlled Trial (RCT), 6 artikel kohort study, dan 1 artikel case study. 


\begin{tabular}{|c|c|c|c|c|}
\hline $\begin{array}{l}\text { Penulis } \\
\text { (Tahun); } \\
\text { Negara } \\
\end{array}$ & Judul & Metode & Hasil Pengukuran & Hasil \\
\hline $\begin{array}{l}\text { Miller et al., } \\
\text { (2014); USA }\end{array}$ & $\begin{array}{l}\text { Reduced Length of } \\
\text { Hospital Stay in } \\
\text { Colorectal Surgery } \\
\text { after } \\
\text { Implementation of } \\
\text { an Enhanced } \\
\text { Recovery Protocol }\end{array}$ & $\begin{array}{l}\text { quantitative } \\
\text { observational } \\
\text { comparative }\end{array}$ & $\begin{array}{l}\text { Primary outcome: } \\
\text { Tingkat LOS } \\
\text { Secondary Outcome: } \\
\text { Readmission Rate, UTI, } \\
\text { SCI, dan tingkat } \\
\text { kematian }\end{array}$ & $\begin{array}{l}\text { Primary Outcome: } \\
\text { Rata-rata lama tinggal (LOS) adalah } 5 \\
\text { hari pada kelompok ERAS } \\
\text { dibandingkan dengan } 7 \text { hari pada } \\
\text { kelompok tradisional }(\mathrm{P}<0,001) . \\
\text { Secondary Outcome: } \\
\text { Penurunan LOS signifikan untuk kedua } \\
\text { prosedur terbuka (median } 6 \text { vs } 7 \text { hari, } \mathrm{P} \\
=0,01) \text {, dan prosedur laparoskopi (4 vs } \\
6 \text { hari, } \mathrm{P}<0,0001) \text {. Pasien ERAS } \\
\text { memiliki lebih sedikit infeksi saluran } \\
\text { kemih }(13 \% \text { vs } 24 \%, \mathrm{P}=0,03) \text {. Tingkat } \\
\text { readmisi lebih rendah pada pasien ERAS } \\
(9,8 \% \text { vs } 20,2 \%, \mathrm{P}=0,02) .\end{array}$ \\
\hline $\begin{array}{l}\text { Wijk, } \\
\text { Franzen, } \\
\text { Ljungqvist, \& } \\
\text { Nilsson, } \\
\text { (2014); } \\
\text { Sweden }\end{array}$ & $\begin{array}{l}\text { Implementing a } \\
\text { structured } \\
\text { Enhanced } \\
\text { Recovery After } \\
\text { Surgery (ERAS) } \\
\text { protocol reduces } \\
\text { length of stay after } \\
\text { abdominal } \\
\text { hysterectomy }\end{array}$ & $\begin{array}{l}\text { Studi } \\
\text { observasional. }\end{array}$ & $\begin{array}{l}\text { Outcome primery } \\
\text { Lama rawat inap dan } \\
\text { proporsi pasien yang } \\
\text { mencapai target rawat } \\
\text { inap ( } 2 \text { hari). }\end{array}$ & $\begin{array}{l}\text { Lama tinggal secara signifikan } \\
\text { berkurang pada populasi penelitian } \\
\text { setelah memperkenalkan protokol ERAS } \\
\text { dari rata-rata } 2,6(\mathrm{SD} 1,1) \text { hari menjadi } \\
\text { rata-rata } 2,3(\mathrm{SD} 1,2) \text { hari }(\mathrm{p}=0,011) \text {. } \\
\text { Proporsi pasien yang dipulangkan pada } \\
2 \text { hari meningkat secara signifikan dari } \\
56 \% \text { sebelum ERAS menjadi } 73 \% \\
\text { setelah ERAS }(\mathrm{p}=0,012) \text {. }\end{array}$ \\
\hline $\begin{array}{l}\text { Teeuwen, } \\
\text { Bleichrodt, } \\
\text { Jong, Goor, \& } \\
\text { Bremers, } \\
\text { (2011); } \\
\text { Netherlands }\end{array}$ & $\begin{array}{l}\text { Enhanced } \\
\text { recovery after } \\
\text { surgery versus } \\
\text { conventional } \\
\text { perioperative care } \\
\text { in rectal surgery. }\end{array}$ & Kohort study & $\begin{array}{l}\text { Primary Outcome } \\
\text { mengenai target jalur } \\
\text { cepat, lama tinggal di } \\
\text { rumah sakit, kematian, } \\
\text { komplikasi, } \\
\text { relaparotomi, dan } \\
\text { penerimaan kembali } \\
\text { dikumpulkan. }\end{array}$ & $\begin{array}{l}41 \text { pasien dalam kelompok pemulihan } \\
\text { ditingkatkan dibandingkan dengan } 82 \\
\text { pasien yang menerima kasus yang } \\
\text { menerima perawatan konvensional. } \\
\text { Lama tinggal di rumah sakit (median: } 8 \\
\text { hari vs } 12 \text { hari, } \mathrm{P}<.005 \text { ) berkurang pada } \\
\text { pemulihan yang ditingkatkan setelah } \\
\text { kelompok operasi. }\end{array}$ \\
\hline $\begin{array}{l}\text { Sarin et al., } \\
\text { 2016); USA }\end{array}$ & $\begin{array}{l}\text { Successful } \\
\text { implementation of } \\
\text { an Enhanced } \\
\text { Recovery After } \\
\text { Surgery program } \\
\text { shortenslength of } \\
\text { stay and improves } \\
\text { postoperativepain, } \\
\text { and bowel and } \\
\text { bladder function } \\
\text { aftercolorectal } \\
\text { surgery }\end{array}$ & Case Control & $\begin{array}{l}\text { Primary outcome: } \\
\text { LOS dan tingkat } \\
\text { readmisi } \\
\text { Secondary outcome } \\
\text { Skor nyeri pasca } \\
\text { operasi, konsumsi } \\
\text { opioid, mual dan } \\
\text { muntah pasca operasi } \\
\text { dan waktu makan padat } \\
\text { pertama }\end{array}$ & $\begin{array}{l}\text { ERAS menurunkan lama rawat inap } \\
\text { total rata-rata rumah sakit }(6,4 \text { hingga } \\
4,4 \text { hari) dan lama rawat inap pasca } \\
\text { prosedur }(6,0 \text { hingga } 4,1 \text { hari }) \text {. Tingkat } \\
\text { penerimaan kembali semua sebab } \\
\text { selama } 30 \text { hari menurun dari } 21 \text { menjadi } \\
9,4 \% \text {. Skor nyeri membaik pada hari } 0 \\
\text { pasca operasi }(3,2-2,1) \text { dan hari } 1(3,2- \\
2,6) \text { meskipun opioid menurun. Waktu } \\
\text { rata-rata untuk makanan padat pertama } \\
\text { menurun dari } 4,7 \text { menjadi } 2,7 \text { hari. }\end{array}$ \\
\hline $\begin{array}{l}\text { Thiele et al., } \\
\text { (2015); USA }\end{array}$ & $\begin{array}{l}\text { Standardization of } \\
\text { Care: Impact of an } \\
\text { Enhanced } \\
\text { Recovery Protocol } \\
\text { on Length of Stay, } \\
\text { Complications, } \\
\text { and Direct Costs } \\
\text { after Colorectal } \\
\text { Surgery }\end{array}$ & $\begin{array}{l}\text { Quasi- } \\
\text { experiment }\end{array}$ & $\begin{array}{l}\text { Primary Outcome: } \\
\text { Length of stay } \\
\text { Secondary Outcome: } \\
\text { LOS yang tidak } \\
\text { disesuaikan komplikasi } \\
\text { bedah, kembalinya } \\
\text { fungsi usus. }\end{array}$ & $\begin{array}{l}\text { Primary Outcome: } \\
\text { Lama rawat berkurang pada semua } \\
\text { pasien sebanyak } 2,3 \text { hari } \\
\text { (dari } 6,8 \pm 4,7 \text { [median } 5 \text { ] hari ke } 4,6 \pm \\
3,6 \text { [median } 3 \text { hari; } p=0,0002 \text { ) } \\
\text { Secondary Outcome: } \\
\text { - } \quad \text { Insiden komplikasi bedah berkurang } \\
\quad \text { dari } 30,1 \% \text { hingga } 14,7 \% \text { (p } \\
\quad=0,007) . \\
\text { - Waktu untuk buang air besar } \\
\quad \text { pertama lebih lebih cepat } 1.9-1.7\end{array}$ \\
\hline
\end{tabular}




\begin{tabular}{|c|c|c|c|c|}
\hline & & & & $\begin{array}{l}\text { hari vs } 2.3 \text { - } 1.6 \text { hari dibandingkan } \\
\text { kelompok perawatan biasa }\end{array}$ \\
\hline $\begin{array}{l}\text { Zeng, Liu, } \\
\text { Zhou, \& } \\
\text { Wang, (2017); } \\
\text { Cina }\end{array}$ & $\begin{array}{l}\text { Enhanced } \\
\text { recovery } \\
\text { programme } \\
\text { following } \\
\text { laparoscopic } \\
\text { colorectal } \\
\text { resection for } \\
\text { elderly patients }\end{array}$ & RCT & $\begin{array}{l}\text { Kembalinya fungsi } \\
\text { gastrointestinal, waktu } \\
\text { untuk flatus pertama. } \\
\text { tingkat komplikasi, } \\
\text { lama tinggal rumah } \\
\text { sakit. }\end{array}$ & $\begin{array}{l}\text { Kembalinya fungsi gastrointestinal } \\
\text { pasca operasi secara signifikan lebih } \\
\text { cepat pada Grup A dibandingkan dengan } \\
\text { Grup } \mathrm{B} \text {, termasuk waktu untuk flatus } \\
\text { pertama ( } 2 \text { banding } 3 \text { hari, } \mathrm{P}<0,001 \text { ), } \\
\text { tinja pertama ( } 3 \text { banding } 4 \text { hari, } \mathrm{P}= \\
0,001 \text { ) dan asupan oral ( } 1 \text { versus } 4 \text { hari, } \\
\mathrm{P}<0,001 \text { ). Kelompok A dikaitkan } \\
\text { dengan tingkat komplikasi pasca operasi } \\
\text { keseluruhan yang lebih rendah }(26,6 \% \\
\text { berbanding } 44,6 \%, \mathrm{P}=0,004) \text { dan } \\
\text { tingkat komplikasi umum }(14,9 \% \\
\text { berbanding } 31,2 \%, \mathrm{P}=0,004) \text {. Median } \\
\text { tinggal di rumah sakit pasca operasi } \\
\text { adalah } 6 \text { hari di Grup A dan } 8 \text { hari di } \\
\text { Grup B (P }<0,001) \text {, masing-masing. }\end{array}$ \\
\hline $\begin{array}{l}\text { Haines et al., } \\
(2013) ; \\
\text { Australia }\end{array}$ & $\begin{array}{l}\text { Association of } \\
\text { postoperative } \\
\text { pulmonary } \\
\text { complications with } \\
\text { delayed } \\
\text { mobilisation } \\
\text { following major } \\
\text { abdominal } \\
\text { surgery: an } \\
\text { observational } \\
\text { cohort study. }\end{array}$ & $\begin{array}{l}\text { Studi kohort } \\
\text { prospektif, } \\
\text { observasional. }\end{array}$ & $\begin{array}{l}\text { Primary outcome } \\
\text { Kejadian, dan faktor } \\
\text { risiko untuk, komplikasi } \\
\text { paru pasca operasi, } \\
\text { hambatan mobilisasi } \\
\text { dan lama tinggal. }\end{array}$ & $\begin{array}{l}\text { Insiden komplikasi paru pasca operasi } \\
\text { adalah } 39 \% \text {. Jenis sayatan dan waktu } \\
\text { untuk memobilisasi jauh dari tempat } \\
\text { tidur secara independen terkait dengan } \\
\text { diagnosis komplikasi paru pasca operasi. } \\
\text { Perkembangan komplikasi paru pasca } \\
\text { operasi meningkatkan lama perawatan di } \\
\text { rumah sakit rata-rata (16 vs } 13 \text { hari; } \mathrm{P}= \\
0,046) \text {. }\end{array}$ \\
\hline $\begin{array}{l}\text { Silva, Li, \& } \\
\text { Rickard, } \\
\text { (2012); } \\
\text { Australia }\end{array}$ & $\begin{array}{l}\text { Does the addition } \\
\text { of deep breathing } \\
\text { exercises to } \\
\text { physiotherapy- } \\
\text { directed early } \\
\text { mobilisation alter } \\
\text { patient outcomes } \\
\text { following high- } \\
\text { risk open upper } \\
\text { abdominal } \\
\text { surgery? Cluster } \\
\text { randomized } \\
\text { controlled trial }\end{array}$ & RCT & $\begin{array}{l}\text { Primary outcome } \\
\text { PPC dan hasil pasca } \\
\text { operasi lama tinggal } \\
\text { (LOS) }\end{array}$ & $\begin{array}{l}\text { Tidak ada perbedaan yang signifikan } \\
\text { dalam PPC antara Grup A dan B. LOS } \\
\text { untuk Grup A \{rata-rata 10,7 hari } \\
\text { [standar deviasi (SD) 5.0] hari\} secara } \\
\text { signifikan lebih pendek daripada LOS } \\
\text { untuk Grup B [rata-rata 16,7 (SD 9,7) } \\
\text { hari] dan C [rata-rata 15.2 (SD 9.8) hari; } \\
\mathrm{P}=0,036 \text { ]. }\end{array}$ \\
\hline $\begin{array}{l}\text { Teeuwen, } \\
\text { Bleichrodt, } \\
\text { Strik, \& } \\
\text { Groenewou, } \\
\text { (2010) } \\
\text { Netherlands }\end{array}$ & $\begin{array}{l}\text { Enhanced } \\
\text { recovery after } \\
\text { surgery (ERAS) } \\
\text { versus } \\
\text { conventional } \\
\text { postoperative care } \\
\text { in colorectal } \\
\text { surgery }\end{array}$ & $\begin{array}{l}\text { Kohort } \\
\text { prospective }\end{array}$ & $\begin{array}{l}\text { Primary outcome } \\
\text { Mortalitas dan } \\
\text { morbiditas. } \\
\text { Secondary outcome } \\
\text { lama tinggal di rumah } \\
\text { sakit }\end{array}$ & $\begin{array}{l}61 \text { pasien yang diobati menurut program } \\
\text { ERAS dibandingkan dengan } 122 \text { pasien } \\
\text { yang menerima perawatan pasca operasi } \\
\text { konvensional. Morbiditas lebih rendah } \\
\text { pada kelompok ERAS dibandingkan } \\
\text { dengan kelompok kontrol (masing- } \\
\text { masing } 14,8 \% \text { berbanding } 33,6 \% ; \mathrm{P}= \\
<0,01 \text { ). Pasien dalam kelompok ERAS } \\
\text { menerima cairan yang lebih sedikit dan } \\
\text { menghabiskan lebih sedikit hari di } \\
\text { rumah sakit (median } 6 \text { hari, kisaran } 3-50 \\
\text { vs median } 9 \text { hari, kisaran } 3-138 ; \mathrm{P}= \\
0,032 \text { ). }\end{array}$ \\
\hline $\begin{array}{l}\text { (Leeden et al., } \\
\text { 2015) }\end{array}$ & $\begin{array}{l}\text { Early enforced } \\
\text { mobilisation }\end{array}$ & $\begin{array}{l}\text { Quasi } \\
\text { experiment }\end{array}$ & $\begin{array}{l}\text { Protokol mobilisasi } \\
\text { yang dipaksakan }\end{array}$ & $\begin{array}{l}\text { Dalam berbagai kelompok bedah, antara } \\
48 \% \text { dan } 56 \% \text { pasien dapat berjalan }\end{array}$ \\
\hline
\end{tabular}

Volume 9, Nomor 1, Februari 2021 


\begin{tabular}{|c|c|c|c|}
\hline & $\begin{array}{l}\text { following surgery } \\
\text { for gastrointestinal } \\
\text { cancer: feasibility } \\
\text { and outcomes }\end{array}$ & $\begin{array}{l}\text { dianggap layak jika } \\
\text { setidaknya } 50 \% \text { pasien } \\
\text { dapat berjalan } \\
\text { jarak terjadwal pada } \\
\text { hari pasca operasi } 1 . \\
\text { Perbedaan pra dan } \\
\text { pasca implementasi } \\
\text { pada komplikasi paru } \\
\text { pasca operasi (PPC), } \\
\text { panjang tinggal di } \\
\text { rumah sakit (LOS) dan } \\
\text { tingkat penerimaan } \\
\text { ulang. }\end{array}$ & $\begin{array}{l}\text { sesuai jadwal pada pasca operasi hari } 1, \\
\text { yang dianggap layak. Namun, tidak ada } \\
\text { pasien yang telah menjalani reseksi } \\
\text { esofagus yang dapat berjalan hari pasca } \\
\text { operasi } 1 \text {. Tidak termasuk pasien ini dari } \\
\text { analisis, ditemukan penurunan PPC yang } \\
\text { signifikan (rasio odds } 0,08, \text { kepercayaan } \\
95 \% \text { interval } 0,010 \text { hingga } 0,71, \mathrm{P}= \\
0,023 \text { ) setelah implementasi mobilisasi } \\
\text { yang dipaksakan. Perbedaan dalam LOS } \\
\text { dan tingkat penerimaan ulang tidak } \\
\text { signifikan. }\end{array}$ \\
\hline $\begin{array}{l}\text { Lee et al., } \\
\text { (2011); Korea }\end{array}$ & $\begin{array}{l}\text { Comparison of } \\
\text { early mobilization } \\
\text { and diet } \\
\text { rehabilitation } \\
\text { program with } \\
\text { conventional care } \\
\text { after laparoscopic } \\
\text { colon surgery }\end{array}$ & $\begin{array}{l}\text { Primary outcome } \\
\text { waktu pemulihan, } \\
\text { diukur dengan kriteria } \\
\text { diet yang dapat } \\
\text { ditoleransi selama } 24 \\
\text { jam, ambulasi aman, } \\
\text { bebas analgesik, dan } \\
\text { status afebril tanpa } \\
\text { komplikasi besar. } \\
\text { Secondary outcome } \\
\text { rawat inap di rumah } \\
\text { sakit. }\end{array}$ & $\begin{array}{l}\text { Waktu pemulihan lebih pendek pada } \\
\text { kelompok program rehabilitasi daripada } \\
\text { pada kelompok perawatan konvensional } \\
\text { (median (kisaran interkuartil), masing- } \\
\text { masing } 4(3-5) \text { vs } 6(5-7) \text {, masing- } \\
\text { masing; } \mathrm{P}<.0001) \text {. Tidak ada perbedaan } \\
\text { dalam perawatan di rumah sakit pasca } \\
\text { operasi antara } 2 \text { kelompok (kelompok } \\
\text { program rehabilitasi, } 7 \text { (6-8) d vs } \\
\text { kelompok perawatan konvensional, } 8 \text { (7- } \\
\text { 9) d; } \mathrm{P}=0,065) \text {. }\end{array}$ \\
\hline
\end{tabular}
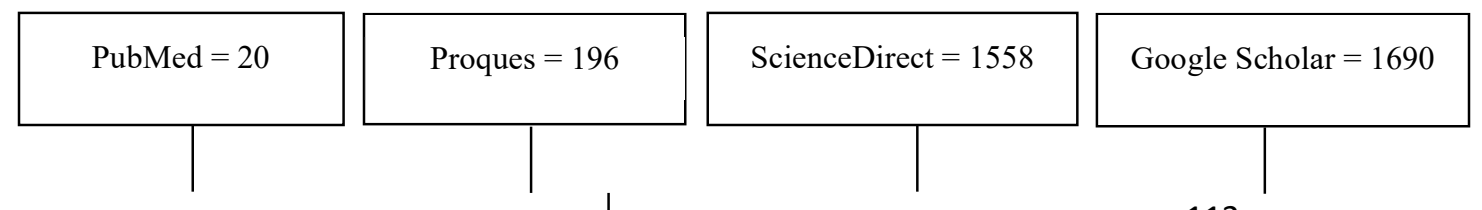

Artikel yang diidentifikasi 


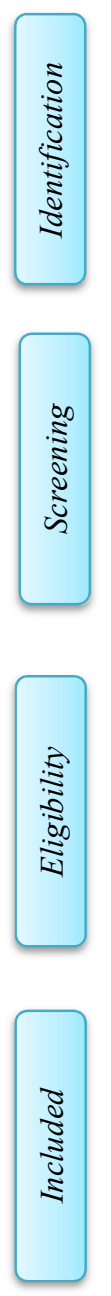

Exclusion:

Tidak sesuai dengan pertanyaan penelitian $(n=3)$

\begin{tabular}{|c|c|c|}
\multicolumn{2}{l}{} & \multicolumn{1}{c|}{} \\
\hline RCT & Kohort Study & Case Study \\
\hline 4 & 6 & 1 \\
\hline
\end{tabular}

Gambar 1.

Diagram PRISMA 


\section{HASIL PENELITIAN}

Dalam tinjauan sistematis ini, terhadap 11 artikel yang telah di screening dan memenuhi kriteria penelitian. Dimana 4 artikel merupakan RCT, 6 artikel kohort studi, dan 1 artikel case studi. Artikel-artikel tersebut dipublikasikan antara tahun 2010 hingga 2019 dengan intervensi mobilisasi dini pada ERAS dengan pasien post operasi laparatomi.

Dari hasil artikel yang diulas internvensi ERAS pada fase postoperative berkontribusi terhadap lama hari rawat diantaranya penelitian yang dilakukan oleh Almeida et al., (2017) pada pasien yang menjalani operasi kolorektal terbuka atau laparoskopi selama 2 periode waktu, sebelum dan sesudah implementasi protokol ERAS dibagi dalam 2 kelompok yang terdiri dari 99 pasien dalam kelompok perawatan tradisional dan 142 pada kelompok ERAS didapatkan hasil rata-rata lama tinggal (LOS) adalah 5 hari pada kelompok ERAS dibandingkan dengan 7 hari pada kelompok tradisional ( $\mathrm{P}<0,001)$. Penurunan LOS signifikan untuk prosedur terbuka (median 6 vs 7 hari, $P$ $=0,01$ ), dan prosedur laparoskopi (4 vs 6 hari, $\mathrm{P}<0,0001)$. Penelitian juga oleh Wijk et al., (2014) pada 85 pasien yang menjalani histerektomi abdominal untuk indikasi jinak atau ganas didapatkan hasil lama hari rawat secara signifikan berkurang pada populasi penelitian setelah memperkenalkan protokol ERAS dari rata-rata 2,6 (SD 1,1) hari menjadi rata-rata $2,3(\mathrm{SD} 1,2)$ hari $(\mathrm{p}=0,011)$. Proporsi pasien yang dipulangkan pada 2 hari meningkat secara signifikan dari $56 \%$ sebelum ERAS menjadi $73 \%$ setelah ERAS $(\mathrm{p}=0,012)$. Sementara penelitian yang di lakukan oleh Teeuwen et al., (2011) yang dibagi dalam 2 kelompok terdiri dari 41 pasien dalam kelompok ERAS dibandingkan dengan 82 pasien yang mendapatkan perawatan konvensiona didapatkan hasil lama hari rawat di rumah sakit (median: 8 hari vs 12 hari, $\mathrm{P}<.005$ ). hasil yang sama didapatkan lama hari rawat yakni dengan ERAS dapat menurunkan lama rawat inap total rata-rata rumah sakit $(6,4$ hingga 4,4 hari) dan lama rawat inap pasca prosedur (6,0 hingga 4,1 hari) (Sarin et al., 2016).

Thiele et al., (2015) yang memberikan intervensi kepada pasien dengan ERAS lama rawat berkurang pada semua pasien sebanyak 2,3 hari (dari 6,8 \pm 4,7 [median 5] hari ke 4,6 \pm 3,6 [median 3 hari; $p=0,0002$ ). Zeng et al., (2017) yang menyelidiki kelayanakan dan keamanan dari ERAS pada pasien berusia $\geq 75$ tahun yang menjalani operasi laparoskopi untuk kanker kolorektal yang dibagi dalam 2 kelompok terdiri dari 94 pasien dengan ERAS dan 157 pasien dengan perawatan konvensional didapatkan lama rawat pasca operasi 6 hari pada kelompok ERAS dan 8 hari pada kelompok perawatan konvensional dengan nilai $\mathrm{P}$ $<0,001)$. Sementara Teeuwen et al., (2010) yang memberikan intervensi dengan ERAS pada 61 pasien dibandingkan 122 pasien dengan perawatan konvensional didapatkan hasil lama rawat dirumah sakit 6 vs 9 hari.

Dari 11 terdapat 4 artikel yang menjelaskan mobilisasi dini pada protokol ERAS berpengaruh terhadap lama rawat, tetapi hanya 2 artikel yang terdapat perbedaan signifikan lama hari rawat setelah diberikan intervensi diantaranya penelitian yang dilakukan oleh Haines et al., (2013) pada pasien yang menjalani operasi perut beresiko tinggi untuk mengukur kejadian 
komplikasi paru pasca operasi, faktor resiko diagnosis komplikasi paru, dan hambatan mobilisasi didapatkan hasil lama hari rawat meningkat karena komplikasi rata-rata 16 vs 13 hari dengan nilai $\mathrm{p}=0,046$ sementara penelitian yang dilakukan oleh Silva et al., (2012) pada 86 pasien yang telah menjalani operasi laparatomi yang dibagi dalam 3 kelompok terdiri dari 28 pasien di group A diberikan intervensi mobilisasi dini, sebanyak 28 pasien di group B diberikan intervensi mobilisasi dini plus latihan pernapasan, dan 30 pasien di group $\mathrm{C}$ diberikan intervensi mobilisasi dini yang tertunda selama 3 hari plus latihan pernapasan didapatkan hasil LOS untuk Grup A \{rata-rata 10,7 hari [standar deviasi (SD) 5.0] hari\} secara signifikan lebih pendek daripada LOS untuk Grup B [rata-rata 16,7 (SD 9,7) hari] dan $\mathrm{C}$ [rata-rata 15.2 (SD 9.8) hari; $\mathrm{P}=0,036]$.

Sedangkan 2 artikel menjelaskan mobilisasi dini pada ERAS berpengaruh terhadap LOS namun hasilnya tidak signifikansi diantaranya penelitian yang dilakukan oleh Lee et al., (2011) untuk mengevaluasi kemajuan program ERAS setelah oparasi usus yang terdiri dari 46 pasien diberikan intervensi mobilisasi dini dan diet awal pada ERAS dan 54 pasien dengan perawatan konvensional didapatkan hasil tidak ada perbedaan yang signifikan dalam perawatan di rumah sakit pasca operasi antara 2 kelompok (kelompok program rehabilitasi, 7 (6-8) vs kelompok perawatan konvensional, 8 (7-9) $\mathrm{P}=$ 0,065). Begitujuga penelitian yang dilakukan oleh Leeden et al., (2015) didapatkan hasil lama rawat tidak signifikan setelah diberikan intervensi mobilisasi dini.

\section{PEMBAHASAN}

Terdapat 9 dari 11 artikel yang diulas menjelaskan setelah pemberian intervensi berkurangya lama hari rawat, diantaranya 7 artikel dengan pemberian intervensi protokol ERAS berpengaruh terhadap lama hari rawat seperti peneltian oleh Miller et al., (2016) ratarata lama hari rawat 5 hari pada kelompok intervensi lebih sedikit dibandingkan dengan kelompok konvensional 7 hari, sama halnya dengan Teeuwen et al., (2010) setelah diberikan intervensi lama hari rawat 6 hari vs 9 hari sedangkan ditahun berikutnya Teeuwen et al., (2011) LoS di rumah sakit 8 hari vs 12 hari antara kelompok intervensi dan kontrol.

Sarin et al., (2016) setelah diberikan intervensi protokol ERAS berkurangnya lama hari rawat inap total rata-rata rumah sakit 6,4 hingga 4,4 hari sedangkan LoS pasca operasi 6,0 hingga 4,1 hari sedangkan Thiele et al., (2015) lama hari rawat berkurang sebanyak 2,3 hari pada semua pasien atau 5 hari menjadi 3 hari setelah diberikan intervensi sama halnya dengan Wijk et al., (2014) setelah memperkenalkan protokol ERAS lama hari rawat dari ratarata 2,6 (SD 1,1) hari berkurang menjadi 2,3 (SD 1,2) hari. Sementara Zeng et al., (2017) yang setelah diberikan intervensi ERAS berkurangnya lama hari rawat 6 hari sedangkan kelompok perbandingan 8 hari.

Sedangkan 2 artikel dengan pemberian intervensi mobilisasi dini yang merupakan bagian dari protokol ERAS pada fase postoperative menjelaskan berpengaruh lama hari rawat setelah diberikan intervensi mobilisasi dini diantaranya penelitian Silva et al., (2012) berkurangnya lama hari rawat setelah diberikan intervensi yang dibagi dalam 3 group yakni group A dengan intervensi mobilisasi dini dengan LOS \{rata-rata 10,7 hari [standar deviasi (SD) 5.0] hari\}, group $B$ 
diberikan intervensi mobilisasi dini plus latihan pernapasan dengan LOS [ratarata 16,7 (SD 9,7) hari] dan group $\mathrm{C}$ diberikan intervensi mobilisasi dini yang tertunda selama 3 hari plus latihan pernapasan dengan LOS [rata-rata 15.2 (SD 9.8) ini berarti pada group A lebih sedikit LoS setelah diberikan intervensi mobilisasi dini dibandingkan dengan group B maupun group C sementara penelitian oleh Haines et al., (2013) kurang mobilisasi atau tidak dilakukan mobilisasi setelah operasi dapat meningkat LoS rata-rata 16 hari sedangkan dengan mobilisasi rata-rata 13 hari.

Sementara sisanya 2 artikel yang juga dengan pemberian mobilisasi dini hasilnya tidak signifikansi seperti penelitian oleh Lee et al., (2011) lama hari rawat antara 2 kelompok yakni kelompok intervensi 7 (6-8) hari dan kelompok konvensional 8 (7-9) hari. Begitujuga penelitian yang dilakukan Leeden et al., (2015) didapatkan hasil LoS tidak signifikan setelah diberikan intervensi mobilisasi dini.

\section{KESIMPULAN}

Intervensi protokol ERAS pada fase post operatif mengurangi LoS pasien dirumah sakit.

\section{DAFTAR PUSTAKA}

Ahmed, A., \& Elzohry, A. A. M. (2018). Enhanced Recovery After Surgery : A Better Protocol for Better Outcomes. Sryahwa Publication, 1(1), 1-7.

Almeida, E. P. M. De, Almeida, J. P. De, Landoni, G., Galas, F. R. B. G., Fukushima, J. T., Fominskiy, E., ... Hajjar, L. A. (2017). Early mobilization programme improves functional capacity after major abdominal cancer surgery: a randomized controlled trial. British
Journal of Anaesthesia, 0(0), 1-8. https://doi.org/10.1093/bja/aex250

Barrow, E., Anderson, I. D., Varley, S., Pichel, A. C., Peden, C. J., Saunders, D. I., \& Murray, D. (2013). Current UK practice in emergency laparotomy. General Surgery, 95, 599-603. https://doi.org/10.1308/003588413 X13629960048433

Carmicahel, J. C., Keller, D. S., Baldini, G., Bordeianou, L., Weiss, M. D. E., Lee, M. D. L., ... Steele, S. R. (2017). Clinical Practice Guidelines for Enhanced Recovery. Disease of the Colon \& Rectum, 60(8), 761784.

https://doi.org/10.1097/DCR.0000 000000000883

Carney, M. J., Weissler, J. M., Fox, J. P., Tecce, M. G., \& John, P. (2017). Trends in open abdominal surgery in the United States - Observations from 9,950,759 discharges using the 2009-2013 national inpatient sample (NIS) datasets. The American Journal of Surgery. https://doi.org/10.1016/j.amjsurg.2 017.01 .001

CASP. (2018a). Critical Appraisal Skills Programme (CASP). CASP Checklist a Randomised Controlled Trial, (2018).

CASP. (2018b). Critical Appraisal Skills Programme (CASP). CASP Checklist Cohort Study, (2018).

CASP. (2018c). Critical Appraisal Skills Programme (CASP) Checklist Case Control Study, (2018).

Cohen, J. F., Korevaar, D. A., Altman, D. G., Bruns, D. E., Gatsonis, C. A., Hooft, L., ... Bossuyt, P. M. M. (2016). STARD 2015 guidelines for 
reporting diagnostic accuracy studies: explanation and elaboration. BMJ Open, 6(11), 117.

https://doi.org/10.1136/bmjopen2016-012799

Darmawan, A. A., \& Rihiantoro, T. (2017). PENGETAHUAN, SIKAP DAN PERILAKU MOBILISASI DINI PASIEN POST OPERASI LAPARATOMI. Jurnal Keperawatan, 8, 110-117.

Depkes, R. (2011). Riset kesehatan dasar. Jakarta: Departemen Kesehatan RI.

Depkes, R. (2013). Riset Kesehatan Dasar. Jakarta: Departemen Kesehatan RI.

Haines, K. J., Skinner, E. H., Berney, S., Austin, T., Post, H., \& Investigators, S. (2013). Association of postoperative pulmonary complications with delayed mobilisation following major abdominal surgery: an observational cohort study. Chartered Society of Physiotherapy., 99, 119-125. https://doi.org/10.1016/j.physio.20 12.05 .013

Lee, T., Kang, M. D. S., Kim, M. D. D., Hong, S., Heo, M. D. S. C., \& Park, M. D. K. J. (2011). Comparison of Early Mobilization and Diet Rehabilitation Program With Conventional Care After Laparoscopic Colon Surgery: A Prospective. DISEASES OF THE COLON \&RECTUM, 54(1), 21-28. https://doi.org/10.1007/DCR.0b01 3e3181fcdb3e

Leeden, M. Van Der, Huijsmans, R., Geleijn, E., \& Klerk, E. S. M. D. L. (2015). Early enforced mobilisation following surgery for gastrointestinal cancer: feasibility and outcomes. Physiotherapy, 1-8. https://doi.org/10.1016/j.physio. 20 15.03 .3722

Miller, M. J., Weech-Maldonado, R., Outman, R. C., Ray, M. N., Gary, L. C., Chen, L., ... Saag, K. G. (2016). Evaluating the effectiveness of a patient storytelling DVD intervention to encourage physician-patient communication about nonsteroidal anti-inflammatory drug (NSAID) use. Patient Education and Counseling, 99(11), 1837-1844. https://doi.org/10.1016/j.pec.2016. 06.013

Miller, T. E., Thacker, J. K., White, W. D., Mantyh, C., Migaly, J., Jin, J., ... Frcp, C. (2014). Reduced Length of Hospital Stay in Colorectal Surgery after Implementation of an Enhanced Recovery Protocol. International Anesthesia Research Society, 118(5), 1052-1061. https://doi.org/10.1213/ANE.0000 000000000206

Moher, D., Liberati, A., Tetzlaff, J., Altman, D. G., Altman, D., Antes, G., ... Tugwell, P. (2009). Preferred reporting items for systematic reviews and meta-analyses: The PRISMA statement. PLoS Medicine, $\quad 6(7)$. https://doi.org/10.1371/journal.pm ed.1000097

Olle, L., Tonia, F. Y., \& Demartines, N. (2017). The History of Enhanced Recovery After Surgery and the ERAS Society 1 2. Journal of Lararoendoscopic \& Advanced Surgical Techniques, 27(9), 860862.

https://doi.org/10.1089/lap.2017.03 
50

Sarin, A., Litonius, E. S., Naidu, R., Yost, C. S., Varma, M. G., \& Chen, L. (2016). Successful implementation of an Enhanced Recovery After Surgery program shortens length of stay and improves postoperative pain, and bowel and bladder function after colorectal surgery. $B M C$ Anesthesiology, 1-10. https://doi.org/10.1186/s12871016-0223-0

Silva, Y. R., Li, S. K., \& Rickard, M. J. F. X. (2012). Does the addition of deep breathing exercises to physiotherapy-directed early mobilisation alter patient outcomes following high-risk open upper abdominal surgery? Physiotherapy, 1-7. https://doi.org/10.1016/j.physio.20 12.09.006

Sjamsuhidarat, R., Karnadihardja, W., Prasetyono, T. O. H., \& Rudiman, R. (2010). Buku Ajar Ilmu Bedah Edisi 3. Jakarta: EGC.

Teeuwen, P. H. E., Bleichrodt, R. P., Jong, P. J. M. de, Goor, H. van, \& Bremers, A. J. A. (2011). Enchanced Recovery After Surgery Versus Conventional Perioperative Care in Rectal Surgery. DISEASES OF THE COLON \& RECTUM, 54, 833-839.

https://doi.org/10.1007/DCR.0b01 $3 \mathrm{e} 318216067 \mathrm{~d}$

Teeuwen, P. H. E., Bleichrodt, R. P., Strik, C., \& Groenewoud, J. J. M. (2010). Enhanced Recovery After Surgery ( ERAS ) Versus Conventional Postoperative Care in Colorectal Surgery. J Gastrointest Surg, 14, 88-95. https://doi.org/10.1007/s11605- 009-1037-x

Tengberg, L. T., Cihoric, M., Foss, N. B., Bay-Nielsen, M., Gögenur, I., Henriksen, R., ... Nielsen, L. B. J. (2017). Complications after emergency laparotomy beyond the immediate postoperative period - a retrospective, observational cohort study of 1139 patients. Anaesthesia, $72(3)$, 309-316. https://doi.org/10.1111/anae.13721

Thiele, R. H., Rea, K. M., Turrentine, F. E., Friel, C. M., Hassinger, T. E., Goudreau, B. J., ... Mcmurry, T. L. (2015). Standardization of Care: Impact of an Enhanced Recovery Protocol on Length of Stay , Complications, and Direct Costs after Colorectal Surgery. Journal of the American College of Surgeons, 220(4), 430-443. https://doi.org/10.1016/j.jamcollsur g.2014.12.042

Wijk, L., Franzen, K., Ljungqvist, O., \& Nilsson, K. (2014). Implementing a structured Enhanced Recovery After Surgery ( ERAS ) protocol reduces length of stay after abdominal hysterectomy. ACTA Obstetricia et Gynecologica, 93, 749-756.

https://doi.org/10.1111/aogs.12423

Zeng, W. G., Liu, M. J., Zhou, Z. X., \& Wang, Z. J. (2017). Enhanced recovery programme following laparoscopic colorectal resection for elderly patients. ANZJSurg.Com, (January 2010). https://doi.org/10.1111/ans.14074 